\title{
EVALUATION OF INTESTINAL PRECONDITIONING IN A PORCINE MODEL USING CLASSIC ISCHEMIC PRECONDITIONING OR LUNG RECRUITMENT MANEUVERS
}

\author{
Jonas Claesson, ${ }^{*}$ Stefan Lehtipalo, ${ }^{*}$ Göran Johansson, ${ }^{*}$ Pernilla Abrahamsson, ${ }^{*}$ \\ Richard Palmqvist, ${ }^{\dagger}$ Björn Biber, ${ }^{\ddagger}$ and Ola Winsö ${ }^{*}$ \\ ${ }^{*}$ Department of Surgical and Perioperative Sciences, Anesthesiology and Intensive Care, Umeå University \\ Hospital; ${ }^{\dagger}$ Department of Medical Biosciences, Pathology, Umeå University, Umeå and ${ }^{\ddagger}$ Department of \\ Anesthesiology and Intensive Care Medicine, Göteborg University, Göteborg, Sweden
}

Received 16 Jan 2007; first review completed 5 Feb 2007; accepted in final form 26 Mar 2007

\begin{abstract}
To test the hypotheses that repeated brief intestinal ischemic insults would elicit an intestinal preconditioning response to a subsequent intestinal $I / R$ injury and that a similar response would be elicited by repeated lung recruitment maneuvers (RMs). Randomized experimental controlled animal study. University hospital animal laboratory. Eighteen anesthetized pigs. Animals were randomized to one of three groups, with six animals in each group. Control group 75-min superior mesenteric artery (SMA) occlusion followed by 60-min reperfusion. Ischemic preconditioning group, three 5-minlong SMA occlusions preceding 75-min SMA occlusion and 60-min reperfusion. Recruitment maneuver (RM) group, three 2-min-long RMs preceding 75-min SMA occlusion and 60-min reperfusion. We measured systemic and mesenteric hemodynamic parameters, jejunal mucosal perfusion, net mesenteric lactate flux, jejunal tissue oxygen tension, and mesenteric oxygenation. Every $15 \mathrm{~min}$, jejunal microdialysate samples were collected and analyzed for glucose, lactate, and glycerol. Jejunal tissue samples were collected postmortem. After occlusion of SMA, regional parameters in all groups indicated abolished perfusion and gradually increasing intraluminal microdialysate lactate and glycerol levels. At reperfusion, regional parameters indicated mesenteric hyperperfusion, whereas microdialysis markers of mucosal anaerobic metabolism and cell injury decreased, although not reaching baseline. Histological examination revealed severe mucosal injury in all groups. There were no significant differences between groups in the observed parameters. No protective preconditioning response could be observed when performing repeated brief intestinal ischemic insults or repeated lung $\mathrm{RMs}$ before an intestinal I/R injury.
\end{abstract}

KEYWORDS-Ischemia, reperfusion injury, swine, microdialysis, lactate, glycerol

\section{INTRODUCTION}

Protective effects of ischemic preconditioning (IPC) elicited by short repeated ischemic insults before a major ischemic reperfusion insult have been demonstrated in different tissues and species (1-5). Intestinal IPC has been studied in some species, including rats and dogs $(6,7)$. Protective effects have been observed when evaluating histology, inflammatory markers, metabolism, and apoptosis (8-11). The protective effects of IPC have been differentiated into two different time frames: an early phase immediately after the injury and lasting 3 to $4 \mathrm{~h}$, and a late phase beginning approximately $24 \mathrm{~h}$ after the injury, lasting 3 to 4 days $(12,13)$. Early preconditioning directly affects cellular energy supplies and intracellular energy consumption, whereas the effect of late preconditioning is dependent on protein synthesis of stress-response proteins such as different heat shock proteins and heme oxygenase 1 . Because of variations in $\mathrm{I} / \mathrm{R}$ tolerance,

Address reprint requests to Jonas Claesson, M.D., Department of Surgical and Perioperative Sciences, Anesthesiology and Intensive Care. Umeå University Hospital, SE-901 85 Umeå, Sweden. E-mail: jonas.claesson@vll.se.

This work was supported by grants from the Medical Faculty, Umeå University, and the Tore Nilsson Foundation, Stockholm, Sweden.

This work was performed at the University Animal Laboratory, Department of Surgical and Perioperative Sciences, Anesthesiology and Intensive Care, Umeå University Hospital, Umeå, Sweden.

DOI: $10.1097 /$ shk.0b013e318057da56

Copyright $\odot 2007$ by the Shock Society the intestinal IPC response might vary between species. To our knowledge, intestinal IPC has not previously been studied in the pig. We therefore decided to study the tentative early protective responses of intestinal preconditioning in a porcine model using established methods for measurements of both intestinal tissue oxygenation/metabolism and intestinal tissue injury.

Lung recruitment maneuvers (RMs), brief powerful increases in airway pressure, are used in mechanically ventilated patients with acute lung injury to improve oxygenation and lung aeration. We, and others, have previously shown that such RMs cause short-lasting but severe decreases in mean arterial pressure (MAP), cardiac output, portal blood flow $\left(Q_{\text {port }}\right)$, and mesenteric oxygen delivery (14-17). These changes did not persist beyond $5 \mathrm{~min}$ after RMs. Repeated RMs can hypothetically induce a preconditioning response in different tissues by reducing tissue blood flow and oxygenation less than the ischemic threshold.

Our aims with this study were therefore to test the hypotheses that an early protective response of intestinal IPC can be demonstrated in the small intestine of the pig, and that a similar preconditioning response can be elicited by three repeated RMs.

\section{MATERIALS AND METHODS}

Eighteen female juvenile pigs, with a mean weight of $25.3 \pm 7.2 \mathrm{~kg}$, were used with approval of the University Animal Experiment Ethics Committee. All procedures were carried out according to the guidelines of the National Institutes 
of Health for the care and use of laboratory animals (7th ed., 1996). The methods have previously been described in detail $(18,19)$.

\section{Anesthesia}

Animals were fasted overnight with free access to water. After premedication with ketamine, azaperon, and atropine (i.m.), anesthesia was induced by sodium pentobarbital (10 $\mathrm{mg} \cdot \mathrm{kg}^{-1}$, i.v.), followed by continuous infusions of sodium pentobarbital $\left(4-6 \mathrm{mg} \cdot \mathrm{kg}^{-1} \cdot \mathrm{h}^{-1}\right.$, i.v. $)$, midazolam $\left(0.3 \mathrm{mg} \cdot \mathrm{kg}^{-1} \cdot \mathrm{h}^{-1}\right.$, i.v. $)$ and fentanyl $\left(20 \mu \mathrm{g} \cdot \mathrm{kg}^{-1} \cdot \mathrm{h}^{-1}\right.$, i.v.). No muscle relaxants were used. After tracheostomy, mechanical ventilation with oxygen in air $\left(30 \% \mathrm{O}_{2}\right)$ was performed using pressure-regulated volume control (Evita 4, Dräger, Germany), positive endexpiratory pressure $\left(0 \mathrm{~cm} \mathrm{H} \mathrm{H}_{2} \mathrm{O}\right)$, a tidal volume of $10 \mathrm{~mL} \cdot \mathrm{kg}^{-1}$, and a frequency of 20 to 30 breaths per minute. Ventilation was adjusted to normocapnia as judged by end-tidal $\mathrm{CO}_{2}$ levels (Artema; Artema Medical AB, Sundbyberg, Sweden) and arterial blood gas analyses (ABL-5 autoanalyzer; Radiometer, Copenhagen, Denmark). Blood samples for lactate concentration were analyzed by an automated analyzer (YSI Sport 2300 Stat Plus; Yellow Springs Instruments, Inc., Yellow Springs, Ohio). Core temperature was kept between 37 and $39^{\circ} \mathrm{C}$ using heating blankets.

\section{Instrumentation and measurements}

Instrumentation of the animals was performed as previously described $(18,19)$ and included measurements of portal blood flow, jejunal tissue oxygen tension, and jejunal mucosal perfusion. Cardiac output was measured using the pulmonary artery catheter at end-expiration with $5 \mathrm{~mL}$ of iced $0.9 \% \mathrm{NaCl}$ as indicator. Thermodilution cardiac output data are presented as means of three consecutive measurements within 2 min and not differing more than $10 \%$.

Splenectomy was performed in all animals to eliminate dilution of portal venous blood. All pressure transducers (System DPT-6000, PvB, Triplus; Sweden) were calibrated to atmospheric pressure at the level of the right atrium by a saline column. Continuous data were acquired with the Acknowledge III (Biopac Systems, Inc., Goleta, Calif) as previously described.

\section{Fluid resuscitation}

All animals received i.v. infusions of Ringer acetate $\left(10 \mathrm{~mL} \cdot \mathrm{kg}^{-1} \cdot \mathrm{h}^{-1}\right)$ and hydroxyethylstarch 200/0.6 (Voluven, Fresenius Kabi, Sweden; 2 $6 \mathrm{~mL} \cdot \mathrm{kg}^{-1} \cdot \mathrm{h}^{-1}$ ), with additional boluses given to keep pulmonary artery occlusion pressure (PAOP) in the range of 4 to $7 \mathrm{mmHg}$ during the experiment.

\section{Microdialysis}

Two custom-made microdialysis catheters (CMA 20; CMA, Solna, Sweden) with a membrane length of $30 \mathrm{~mm}$ and a molecular cutoff of $20 \mathrm{kD}$ were inserted into the lumen of the jejunum $2.2 \mathrm{~m}$ proximal to the ileocecal valve and secured with sutures. Two identical microdialysis catheters were inserted into the jejunal wall and secured with a suture immediately proximal to the intraluminal microdialysis catheters. The correct positions of the catheters within the jejunal lumen and wall respectively were verified by inspection at the end of each experiment. The catheters were connected to microdialysis pumps (CMA 102; CMA) and perfused with Ringer solution at $1.5 \mu \mathrm{L} \mathrm{min}{ }^{-1}$. Microvials (vial plastic, $300 \mu \mathrm{L}$, product no. 7431100 ; CMA) collecting the dialysate were replaced every fifteenth minute using automated microfraction collectors (CMA 142; CMA) throughout the study protocol. The dialysate was analyzed directly after sampling for glucose, lactate, pyruvate, and glycerol concentrations using enzymatic reagents followed by colorimetric analysis (CMA 600; CMA).

\section{Histological examination}

Directly after finalizing the experiment, a $20 \times 20$-mm jejunal tissue sample was excised between the two intraluminal microdialysis catheters and rinsed in saline. A $5 \times 10-\mathrm{mm}$ tissue sample was subsequently fixed in $4 \%$ formaldehyde and embedded in paraffin according to routine procedures. Thereafter, $4-\mu \mathrm{m}$-thick cross sections were cut and routinely stained with hematoxylin-eosin. All tissue samples were examined by an independent pathologist blinded to the group belonging to the tissue samples. The histological changes were graded between 0 (normal) and 5 (worst injury) according to a previously described I/R injury score (20).

\section{Recruitment maneuver}

Each RM lasted for $2 \mathrm{~min}$. The ventilator was set to pressure-controlled ventilation with a frequency of 12 breaths per minute, with an inspiratory time of $4 \mathrm{~s}$, and an expiratory time of $1 \mathrm{~s}$ (I-E ratio, 4:1). The peak pressure was set to $40 \mathrm{cmH}_{2} \mathrm{O}$, and the positive end-expiratory pressure was set to $20 \mathrm{cmH}_{2} \mathrm{O}$.

\section{Experimental protocol}

After surgical instrumentation and a 60 -min recovery period, baseline measurements were obtained. All animals then underwent a sequence comprising a $60-\mathrm{min}$ - long intervention period, a 75-min-long intestinal ischemia period, and a 60-minlong reperfusion period. The animals were randomized to one of the following three groups: control (C) group $(n=6)$, IPC group $(n=6)$, and RM group $(n=6)$.

In the $\mathrm{C}$ group, the animals were left undisturbed during the intervention period. In the IPC group, the animals underwent three periods of 5-min-long total occlusions of superior mesenteric artery (SMA), each period followed by $10 \mathrm{~min}$ of reperfusion. In the RM group, the animals underwent three 2-min-long RMs, each followed by a 13-min pause. After these $60 \mathrm{~min}$, animals in all groups then followed the same protocol, an intestinal ischemia period with total SMA occlusion for $75 \mathrm{~min}$, followed by a 60 -min reperfusion.

During the experiment, complete data sets were recorded at 15 -min intervals, but data will be presented only from the following time points: baseline ( $0 \mathrm{~min})$, end of intervention period (60 min), end of ischemia period $(135 \mathrm{~min})$, and end of reperfusion period (195 $\mathrm{min})$.

Recordings included measurements of MAP, heart rate, central venous pressure, mean pulmonary arterial pressure, cardiac index, portal blood flow, portal venous pressure, jejunal mucosal blood flow, and jejunal tissue oxygen tension. Blood samples for blood gas analysis and lactate measurements were drawn from aortic and portal venous catheters in conjunction with the hemodynamic recordings. Samples from the microdialysis catheters were continuously collected at all these time intervals.

\section{Calculations}

Systemic vascular resistance $=(\mathrm{MAP}-\mathrm{CVP}) \cdot$ cardiac output $^{-1} \cdot 80$

Systemic arterial oxygen content $\left(\mathrm{mL} \cdot \mathrm{L}^{-1} ; \mathrm{CaO}_{2}\right)=\mathrm{Hb}\left(\mathrm{g} \cdot \mathrm{L}^{-1}\right) \cdot$ arterial oxygen saturation percentage $\cdot 1.39+0.031 \cdot \mathrm{PaO}_{2}$ (torr)

Portal venous oxygen content $\left(\mathrm{Cpvo}_{2} ; \mathrm{mL} \cdot \mathrm{L}^{-1}\right)=\mathrm{Hb}\left(\mathrm{g} \cdot \mathrm{L}^{-1}\right) \cdot$ portal vein oxygen saturation percentage $\cdot 1.39+0.031 \cdot$ Portal vein oxygen partial pressure (torr).

Mesenteric oxygen delivery $=\left(\mathrm{CaO}_{2}\right) \cdot Q_{\text {port }}$.

Mesenteric oxygen uptake $\left(\mathrm{M}-\mathrm{Vo}_{2}\right)=\left(\mathrm{CaO}_{2}-\mathrm{CpvO}_{2}\right) \cdot Q_{\text {port }}$.

Mesenteric oxygen extraction $=\mathrm{M}-\mathrm{Vo}_{2} \cdot \mathrm{M}-\mathrm{DO}_{2}^{-1} \cdot 100$. $Q_{\text {port }}$.

Net mesenteric lactate flux $=($ Portal venous - arterial lactate concentration $)$

\section{Statistics}

All values are given as mean $\pm \mathrm{SD}$. Comparisons were performed between groups IPC and C and between groups RM and C using analysis of covariance. Analysis of covariance was performed with mean values at end of intervention period, end of ischemia period, and end of reperfusion period as dependent variables and mean values at baseline and group belonging as independent variables in linear regression, respectively. If this analysis indicated statistically significant differences $(P<0.05)$ between groups, a test to exclude statistical interaction was performed. Comparisons within groups over time were performed using a repeated-measures general linear model with Bonferroni correction for multiple testing. The statistical analyses were performed with the SPSS software package (version 13.0; SPSS Inc., Chicago, Ill).

\section{RESULTS}

\section{Effects occurring during intervention period}

Comparisons between groups-No significant differences between groups were found (Tables 1 and 2, Figs. 1-4).

Comparisons within groups-In the $\mathrm{C}$ group, there was a minor decrease in mesenteric oxygen delivery $(P=0.021$; Table 2). In the IPC group, there was an increase in both net mesenteric lactate flux and intraluminal jejunal microdialysate lactate $(P=0.003$ and $P=0.003$, respectively; Table 2, Fig. 1).

\section{Effects occurring during ischemia period}

Comparisons between groups-Net mesenteric lactate flux was higher in the IPC group when compared with the $\mathrm{C}$ group $(P=0.019)$. No other significant differences between groups were found (Tables 1 and 2, Fig. 1-4).

Comparisons within groups - In all groups, a typical pattern was observed during ischemia, with decreased central venous pressure, portal blood flow, jejunal tissue oxygen tension, relative jejunal mucosal perfusion, mesenteric oxygen delivery, jejunal wall microdialysate glucose and increased 
MAP, jejunal intraluminal microdialysate lactate, and jejunal wall microdialysate lactate (Tables 1 and 2, Figs. 1-4). In the C group, jejunal intraluminal microdialysate glycerol was increased (Fig. 3). In the RM group, heart rate was increased,

\section{TABLE 1. Circulatory and respiratory parameters}

Baseline End intervention End ischemia End reperfusion Heart rate (bpm)

$\begin{array}{llrrr}\text { C } & 77 \pm 9 & 77 \pm 10 & 96 \pm 19 & 131 \pm 41 \\ \text { RM } & 93 \pm 17 & 106 \pm 21 & 112 \pm 19^{\mathrm{a}} & 152 \pm 34^{\mathrm{a}} \\ \text { IPC } & 95 \pm 20 & 97 \pm 24 & 127 \pm 44 & 146 \pm 38^{\mathrm{a}}\end{array}$

MAP $(\mathrm{mmHg})$

$\begin{array}{lclll}\text { C } & 83 \pm 8 & 80 \pm 7 & 123 \pm 10^{\mathrm{a}} & 82 \pm 15 \\ \mathrm{RM} & 95 \pm 14 & 85 \pm 17 & 125 \pm 12^{\mathrm{a}} & 83 \pm 7 \\ \text { IPC } & 102 \pm 18 & 99 \pm 18 & 134 \pm 27^{\mathrm{a}} & 92 \pm 21\end{array}$

Central venous pressure $(\mathrm{mmHg})$

$\begin{array}{lclll}\mathrm{C} & 6 \pm 0 & 6 \pm 1 & 3 \pm 1^{\mathrm{a}} & 3 \pm 1^{\mathrm{a}} \\ \mathrm{RM} & 5 \pm 1 & 5 \pm 1 & 4 \pm 1^{\mathrm{a}} & 3 \pm 1^{\mathrm{a}} \\ \mathrm{IPC} & 5 \pm 1 & 4 \pm 1 & 2 \pm 1^{\mathrm{a}} & 2 \pm 1^{\mathrm{a}} \\ \mathrm{PAOP}(\mathrm{mmHg}) & & & \\ \mathrm{C} & 6 \pm 1 & 6 \pm 1 & 4 \pm 2 & 3 \pm 2^{\mathrm{a}} \\ \mathrm{RM} & 6 \pm 1 & 5 \pm 1 & 5 \pm 1 & 4 \pm 2 \\ \mathrm{IPC} & 5 \pm 2 & 5 \pm 1 & 3 \pm 2 & 3 \pm 1^{\mathrm{a}}\end{array}$

Cardiac index $\left(\mathrm{mL} \cdot \mathrm{min}^{-1} \cdot \mathrm{kg}^{-1}\right)$

$\begin{array}{lllll}\text { C } & 153 \pm 11 & 140 \pm 13 & 169 \pm 37 & 223 \pm 50 \\ \text { RM } & 168 \pm 31 & 160 \pm 19 & 185 \pm 44 & 234 \pm 53^{\mathrm{a}} \\ \text { IPC } & 194 \pm 45 & 179 \pm 35 & 219 \pm 89 & 244 \pm 87\end{array}$

$\mathrm{pH}$

$\begin{array}{lllll}\mathrm{C} & 7.47 \pm 0.03 & 7.46 \pm 0.03 & 7.50 \pm 0.05 & 7.41 \pm 0.07 \\ \mathrm{RM} & 7.47 \pm 0.05 & 7.43 \pm 0.05 & 7.47 \pm 0.07 & 7.41 \pm 0.03 \\ \mathrm{IPC} & 7.48 \pm 0.02 & 7.49 \pm 0.04 & 7.49 \pm 0.04 & 7.42 \pm 0.05\end{array}$

$\mathrm{PaCO}_{2}$ (torr)

$\begin{array}{lllll}\mathrm{C} & 36 \pm 3 & 36 \pm 2 & 33 \pm 4 & 39 \pm 5 \\ \mathrm{RM} & 37 \pm 4 & 39 \pm 3 & 33 \pm 3 & 39 \pm 3 \\ \mathrm{IPC} & 37 \pm 2 & 37 \pm 3 & 33 \pm 3 & 39 \pm 5\end{array}$

$\mathrm{PaO}_{2}$ (torr)

$\begin{array}{lllll}\mathrm{C} & 117 \pm 20 & 121 \pm 16 & 110 \pm 17 & 100 \pm 19^{\mathrm{a}} \\ \mathrm{RM} & 112 \pm 14 & 103 \pm 9 & 113 \pm 18 & 104 \pm 14 \\ \mathrm{IPC} & 115 \pm 7 & 118 \pm 12 & 116 \pm 17 & 108 \pm 13\end{array}$

Portal vein oxygen partial pressure (torr)

$\begin{array}{lllll}\text { C } & 43 \pm 5 & 42 \pm 4 & 37 \pm 5 & 61 \pm 9^{\mathrm{a}} \\ \text { RM } & 43 \pm 7 & 40 \pm 6 & 36 \pm 6 & 66 \pm 7^{\mathrm{a}} \\ \text { IPC } & 46 \pm 4 & 48 \pm 4 & 38 \pm 2^{\mathrm{a}} & 65 \pm 5^{\mathrm{a}}\end{array}$

Portal vein oxygen saturation (\%)

\begin{tabular}{lllll} 
C & $74 \pm 6$ & $71 \pm 4$ & $58 \pm 10$ & $87 \pm 8^{\mathrm{a}}$ \\
$\mathrm{RM}$ & $72 \pm 10$ & $64 \pm 8$ & $56 \pm 13$ & $91 \pm 4^{\mathrm{a}}$ \\
$\mathrm{IPC}$ & $77 \pm 5$ & $78 \pm 4$ & $53 \pm 6^{\mathrm{a}}$ & $90 \pm 3^{\mathrm{a}}$ \\
\hline
\end{tabular}

Data are presented as mean \pm SD.

${ }^{a}$ Significant differences within groups versus baseline values $(P<0.05)$.

Statistical testing between groups was performed, but no significant differences were found.
TABLE 2. Regional circulation and metabolism

Baseline End intervention End ischemia End reperfusion

Portal blood flow ( $\mathrm{mL} \cdot \mathrm{min}^{-1} \cdot \mathrm{kg}^{-1}$ )

$\begin{array}{lllll}\mathrm{C} & 25 \pm 10 & 23 \pm 8 & 2 \pm 1^{\mathrm{a}} & 57 \pm 19^{\mathrm{a}} \\ \mathrm{RM} & 27 \pm 9 & 22 \pm 8 & 3 \pm 1^{\mathrm{a}} & 65 \pm 18^{\mathrm{a}} \\ \mathrm{IPC} & 36 \pm 11 & 38 \pm 11 & 3 \pm 2^{\mathrm{a}} & 67 \pm 18\end{array}$

Jejunal tissue oxygen tension (torr)

$\begin{array}{lllll}\mathrm{C} & 56 \pm 16 & 60 \pm 19 & 2 \pm 5^{\mathrm{a}} & 61 \pm 21 \\ \mathrm{RM} & 58 \pm 17 & 51 \pm 19 & 1 \pm 1^{\mathrm{a}} & 60 \pm 25 \\ \mathrm{IPC} & 62 \pm 25 & 58 \pm 30 & 1 \pm 1^{\mathrm{a}} & 60 \pm 26\end{array}$

Relative jejunal mucosal perfusion

$\begin{array}{lllll}\text { C } & 1.00 \pm 0.00 & 0.88 \pm 0.08 & 0.22 \pm 0.14^{\mathrm{a}} & 1.19 \pm 0.54 \\ \mathrm{RM} & 1.00 \pm 0.00 & 1.10 \pm 0.51 & 0.13 \pm 0.10^{\mathrm{a}} & 1.19 \pm 0.82 \\ \text { IPC } & 1.00 \pm 0.00 & 1.09 \pm 0.30 & 0.41 \pm 0.41^{\mathrm{a}} & 1.58 \pm 0.58\end{array}$

Net mesenteric lactate flux ( $\mathrm{nmol} \cdot \mathrm{min}^{-1} \cdot \mathrm{kg}^{-1}$ )

$\begin{array}{lllll}\mathrm{C} & 2.8 \pm 1.0 & 2.1 \pm 0.8 & 2.0 \pm 1.5 & 11.6 \pm 3.6^{\mathrm{a}} \\ \mathrm{RM} & 3.9 \pm 0.8 & 3.5 \pm 3.4 & 3.8 \pm 2.3 & 15.3 \pm 7.2^{\mathrm{a}} \\ \mathrm{IPC} & 1.5 \pm 1.7 & 5.7 \pm 0.8^{\mathrm{a}} & 5.6 \pm 3.6^{\mathrm{b}} & 12.3 \pm 2.6^{\mathrm{a}}\end{array}$

Mesentric oxygen delivery $\left(\mathrm{mL} \cdot \mathrm{min}^{-1} \cdot \mathrm{kg}{ }^{-1}\right)$

$\begin{array}{lllll}\mathrm{C} & 2.9 \pm 0.9 & 2.6 \pm 0.7^{\mathrm{a}} & 0.2 \pm 0.1^{\mathrm{a}} & 5.9 \pm 1.6^{\mathrm{a}} \\ \mathrm{RM} & 3.5 \pm 1.0 & 2.8 \pm 1.1 & 0.3 \pm 0.1^{\mathrm{a}} & 7.2 \pm 1.8^{\mathrm{a}} \\ \mathrm{IPC} & 4.5 \pm 1.2 & 4.7 \pm 1.3 & 0.4 \pm 0.2^{\mathrm{a}} & 7.9 \pm 1.4^{\mathrm{a}}\end{array}$

Mesentric oxygen uptake $\left(\mathrm{mL} \cdot \mathrm{min}^{-1} \cdot \mathrm{kg}^{-1}\right)$

$\begin{array}{lllll}\text { C } & 0.8 \pm 0.3 & 0.7 \pm 0.2 & 0.1 \pm 0.0 & 0.7 \pm 0.7 \\ \text { RM } & 1.0 \pm 0.4 & 1.0 \pm 0.4 & 0.1 \pm 0.1^{\mathrm{a}} & 0.6 \pm 0.2 \\ \text { IPC } & 1.0 \pm 0.2 & 1.0 \pm 0.3 & 0.2 \pm 0.1^{\mathrm{a}} & 0.7 \pm 0.2\end{array}$

Mesentric oxygen extraction ratio (\%)

\begin{tabular}{lllll} 
C & $26 \pm 8$ & $29 \pm 5$ & $42 \pm 10$ & $12 \pm 8^{\mathrm{a}}$ \\
$\mathrm{RM}$ & $28 \pm 10$ & $36 \pm 9$ & $44 \pm 12$ & $8 \pm 2^{\mathrm{a}}$ \\
$\mathrm{IPC}$ & $23 \pm 6$ & $22 \pm 5$ & $48 \pm 6$ & $9 \pm 2^{\mathrm{a}}$ \\
\hline
\end{tabular}

Data are presented as mean \pm SD.

aSignificant differences within groups versus baseline values $(P<0.05)$.

${ }^{\mathrm{b}}$ Differences between groups IPC and C $(P<0.05)$.

whereas mesenteric oxygen uptake was decreased (Tables 1 and 2). In the IPC group, mesenteric oxygen uptake, portal vein oxygen partial pressure, and saturation were decreased, whereas mesenteric oxygen extraction ratio and jejunal

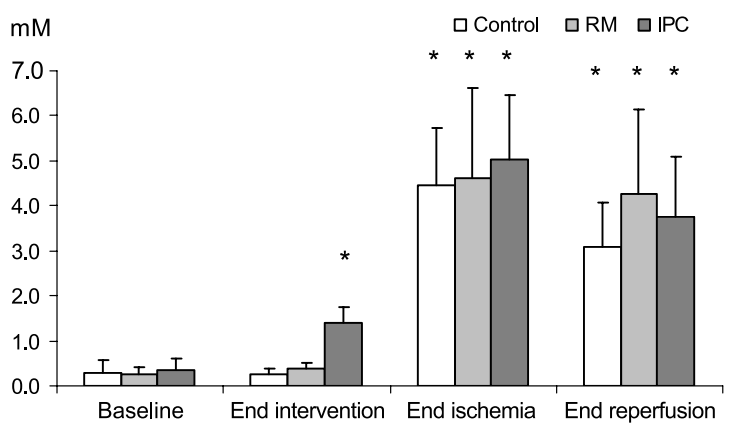

FIG. 1. Jejunal intraluminal microdialysate lactate (mean \pm SD). Asterisk indicates significant difference within groups versus baseline $(P<0.05)$. 


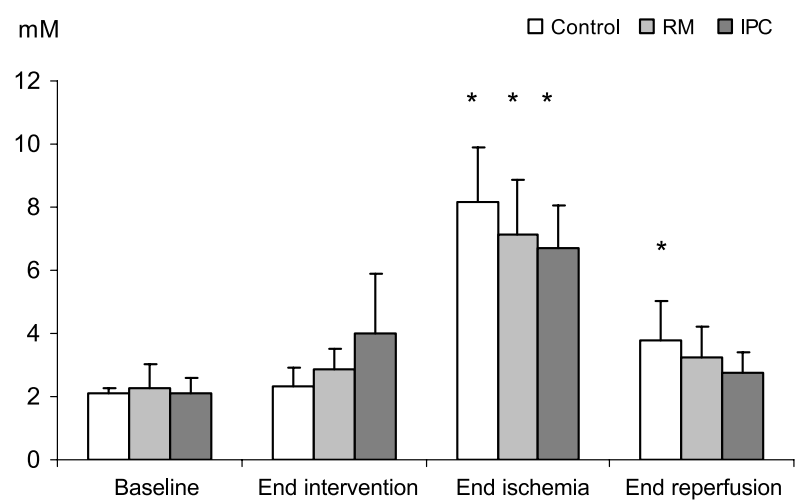

FIG. 2. Jejunal intestinal wall microdialysate lactate (mean \pm SD). Asterisk indicates significant difference within groups versus baseline $(P<0.05)$.

intraluminal microdialysate glycerol were increased (Tables 1 and 2, Fig. 3).

\section{Effects occurring during reperfusion period}

Comparisons between groups-No significant differences between groups were found (Tables 1 and 2, Figs. 1-4).

Comparisons within groups-In all groups, a typical pattern was observed during reperfusion, with increased mesenteric oxygen delivery, net mesenteric lactate flux, jejunal intraluminal microdialysate lactate, portal vein oxygen pressure and saturation, and decreased central venous pressure and mesenteric oxygen extraction ratio (Tables 1 and 2, Fig. 1). In the $\mathrm{C}$ group, $\mathrm{PAOP}$ and $\mathrm{PaO}_{2}$ were decreased, whereas portal blood flow and jejunal wall microdialysate lactate were increased (Tables 1 and 2, Fig. 2). In the RM group, heart rate, cardiac index and portal blood flow were increased (Tables 1 and 2). In the IPC group, PAOP was decreased, whereas heart rate was increased (Table 1).

\section{Histological examination}

Comparisons between groups-There were no significant differences between groups in mean I/R injury score ( $\mathrm{C}$ group, $3.7 \pm 0.5 ; \mathrm{RM}$ group, $4.2 \pm 0.8$; IPC group, $3.7 \pm 0.5)$.

\section{DISCUSSION}

In the present work, we compared the effects of intestinal IPC and repeated RMs versus a $\mathrm{C}$ group on a subsequent intes-

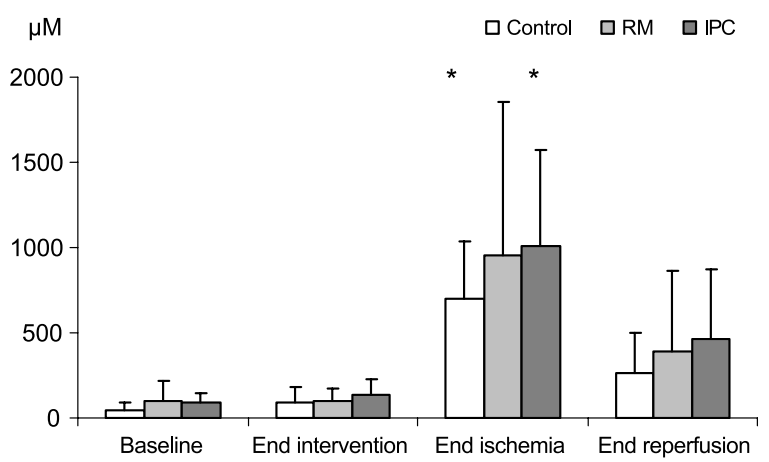

FIG. 3. Jejunal intraluminal microdialysate glycerol (mean \pm SD). Asterisk indicates significant difference within groups versus baseline $(P<0.05)$.

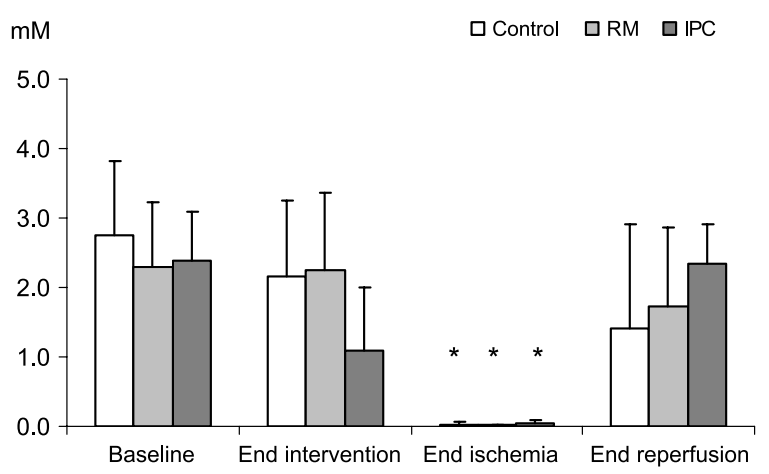

FIG. 4. Jejunal intestinal wall microdialysate glucose (mean \pm SD). Asterisk indicates significant difference within groups versus baseline $(P<0.05)$.

tinal $\mathrm{I} / \mathrm{R}$ injury. In this model, studying juvenile anesthetized pigs, we could not demonstrate any protective effect of intestinal IPC. Neither did repeated RMs with brief increases in intrathoracic pressure and associated decreases in global cardiac output elicit such a protective intestinal preconditioning response.

In all groups, the expected response pattern to occlusion of the SMA was observed, with the systemic circulation adapting to the increased afterload, and all regional parameters indicating abolished perfusion (minimal portal venous blood flow, minimal jejunal mucosal perfusion, abolished intramural microdialysate glucose, severe tissue hypoxia, and gradually increasing intraluminal microdialysate lactate and glycerol levels). When occlusion was relieved and reperfusion established, the expected systemic response of decreasing blood pressure and increasing heart rate was seen. Regional parameters indicated mesenteric hyperperfusion, with increased portal blood flow, jejunal mucosal perfusion, decreased mesenteric oxygen extraction ration. Furthermore, net mesenteric lactate production was greatly increased during and reperfusion, whereas microdialysis markers of mucosal anaerobic metabolism and cell injury decreased, although not reaching baseline levels (microdialysis intraluminal lactate and glycerol actually peaked 15 min after start of reperfusion-data not shown). Histological examination of mucosal tissue samples obtained at the end of the experiment revealed severe mucosal injury in all groups, consistent with the results of the microdialysate and tissue oxygenation results.

In this study, we have shown that using the presented methods for evaluating intestinal circulation, oxygenation, metabolism, and cell injury, expected and relevant changes of an intestinal I/R injury will be detected.

Intraluminal microdialysate analysis of lactate and glycerol has been used by several other authors to describe the changes in intestinal I/R injury, and our results are consistent with the findings of these authors (21-23). However, when comparing absolute microdialysate values, one has to consider the effect of actual microdialysate recovery on the measured substance. When controlling the microdialysate catheters in vitro in glucose solutions of known concentrations, our research group has observed significant variations in recovery $(35.3 \%$ mean recovery rate, with a $5.1 \%$ mean coefficient of variation) (24). This variation will be even more accentuated in vivo, where 
such factors as catheter position, peristalsis, and catheter coating will also affect recovery. This makes it difficult to compare absolute values between individual animals in an experimental series and also between different studies.

In different rat models of intestinal ischemia, a consistent protective IPC response has been observed. Vlasov et al. (7) showed that $10 \mathrm{~min}$ of intestinal ischemia followed by $10 \mathrm{~min}$ of reperfusion before a 90-min-long ischemia period ameliorated intestinal damage. Using a similar model for intestinal IPC (10 min ischemia followed by $10 \mathrm{~min}$ reperfusion) before a 30-min-long ischemia period, Aksoyek et al. (25) showed less bacterial translocation in the preconditioned group at $24 \mathrm{~h}$ postischemia. Aban et al. (26) demonstrated a protective IPC effect on intestinal apoptosis using two cycles of 5-min-long ischemia periods, followed by a 5-min-long period of reperfusion before a 45-min-long ischemia period. In dogs, Ferencz et al. (6) have shown that intestinal IPC with four cycles each of $5 \mathrm{~min}$ of ischemia and $10 \mathrm{~min}$ of reperfusion before autotransplantation (transplanted organs preserved for $3 \mathrm{~h}$ in University of Wisconsin solution) mitigated the oxidative stress.

However, in this study, we could not reproduce these findings of a protective intestinal IPC response in the rat and dog. There are several possible explanations for our findings. The energy metabolism of the jejunum is dependent on two functionally different tissues, the ischemia-tolerant smooth muscle of the jejunal wall that has a low metabolic activity and the jejunal mucosa with highly metabolically active epithelial cells.

One possible explanation for species-dependent responses to intestinal IPC might be differences in intestinal ischemia tolerance dependent on the relative contribution of these different tissues to total jejunal energy metabolism. In the pig, it is estimated that as much as $50 \%$ of the energy is consumed by the ischemia-tolerant smooth muscle layer (27). If this proportion is lower, and the jejunal energy metabolism mainly depends on highly active mucosal tissues, it is likely that this will lead to an increased sensitivity to ischemia, and also easier elicit an intestinal preconditioning response. Furthermore, the amount of xanthine oxidase in tissues, a key enzyme in the formation of reactive oxygen species during reperfusion, varies between species. Intestinal amount of this enzyme has been reported to be low in the pig, and variation in the intestinal amount of this enzyme might well explain speciesdependent differences in preconditioning response (the presence of large amounts increasing the reperfusion injury, thereby also possibly increasing the protective effect of IPC) $(28,29)$.

One limitation of our study is the fact that we used brief periods of intestinal ischemia as preconditioning stimuli. When studying IPC in the heart, periods of $5 \mathrm{~min}$ of ischemia have repeatedly been shown to be sufficient to induce a preconditioning response, whereas periods of 1 to 2 min of ischemia have not elicited such a response (13). Previous studies in rats have shown that intestinal preconditioning can be elicited by periods as brief as 1 to $5 \mathrm{~min}$ of intestinal ischemia $(11,30)$. It is possible that the pig jejunum is more ischemia-tolerant than the rat or dog jejunum, and that a 5-min-long occlusion period was too brief to elicit a response. Because this, to our knowledge, has not been studied earlier, this remains speculative. The duration of our index ischemia in this model was set at $75 \mathrm{~min}$, which in the control group resulted in severe histological mucosal damage. It is possible that the duration of the index ischemia was too long, and that the protective effect of preconditioning was unable to prevent the tissue damage due to the longstanding ischemia. In a pilot study, we varied the duration of the index ischemia between 60 and $120 \mathrm{~min}$, and choose the shortest duration (75 min) of ischemia that resulted in a significant $\mathrm{I} / \mathrm{R}$ injury (data not shown).

Other limitations of our study are the lack of local inflammatory markers such as intraluminal microdialysate cytokines and functional outcome measures such as markers of intestinal permeability. However, in a similar porcine I/R injury model, Solligard et al. (23) demonstrated a significant increase in intestinal permeability and a significant correlation between luminal lactate and venous PEG-4000 used as a marker for intestinal permeability. Comparing intraluminal microdialysate data for lactate and glycerol in our study with those presented by Solligard et al. show the levels to be similar, and we suggest that this indicates a similar degree of intestinal permeability disturbance.

Regarding the small sample size used in our study, one has to consider the statistical power of the present study, especially with a negative result presented. With six animals in each group, we estimate that with an $80 \%$ power, the magnitude of changes detectable were in the $40 \%$ range.

From a clinical point of view, protection against intestinal $\mathrm{I} / \mathrm{R}$ injury would be interesting in settings of aortic aneurysm surgery and small-bowel transplantation. Although the phenomenon of intestinal IPC has been demonstrated in murine and canine models, we were unable to demonstrate such a response in a porcine model, possibly due to species-dependent differences. Whether intestinal IPC as a phenomenon exists in man remains to be proven, and further studies are needed.

To conclude, no protective preconditioning response can be observed when performing repeated brief intestinal ischemic insults or repeated lung RMs before an intestinal I/R injury.

\section{ACKNOWLEDGMENTS}

The authors thank Dr. E. Solligård and Professor G. Ronquist for valuable exchange of ideas. They also thank K. Näslund for skillful technical assistance.

\section{REFERENCES}

1. Li G, Chen S, Lou W, Lu E: Protective effects of ischemic preconditioning on donor lung in canine lung transplantation. Chest 113:1356-1359, 1998.

2. Murry CE, Jennings RB, Reimer KA: Preconditioning with ischemia: a delay of lethal cell injury in ischemic myocardium. Circulation 74:1124-1136, 1986.

3. Stenzel-Poore MP, Stevens SL, Xiong Z, Lessov NS, Harrington CA, Mori M, Meller R, Rosenzweig HL, Tobar E, Shaw TE, et al.: Effect of ischaemic preconditioning on genomic response to cerebral ischaemia: similarity to neuroprotective strategies in hibernation and hypoxia-tolerant states. Lancet 362:1028-1037, 2003.

4. Lee WY, Lee SM: Ischemic preconditioning protects post-ischemic oxidative damage to mitochondria in rat liver. Shock 24:370-375, 2005.

5. Tsai BM, Wang M, March KL, Turrentine MW, Brown JW, Meldrum DR: Preconditioning: evolution of basic mechanisms to potential therapeutic strategies. Shock 21:195-209, 2004. 
6. Ferencz A, Szanto Z, Borsiczky B, Kiss K, Kalmar-Nagy K, Szeberenyi J, Horvath PO, Roth E: The effects of preconditioning on the oxidative stress in small-bowel autotransplantation. Surgery 132:877-884, 2002.

7. Vlasov TD, Smirnov DA, Nutfullina GM: Preconditioning of the small intestine to ischemia in rats. Neurosci Behav Physiol 32:449-453, 2002.

8. Cinel I, Avlan D, Cinel L, Polat G, Atici S, Mavioglu I, Serinol H, Aksoyek S, Oral U: Ischemic preconditioning reduces intestinal epithelial apoptosis in rats. Shock 19:588-592, 2003.

9. McCallion K, Wattanasirichaigoon S, Gardiner KR, Fink MP: Ischemic preconditioning ameliorates ischemia- and reperfusion-induced intestinal epithelial hyperpermeability in rats. Shock 14:429-434, 2000.

10. Sola A, Alfaro V, Pesquero J, Palacios L, Pi F, Rosello-Catafau J, Gelpi E, Hotter $\mathrm{G}$ : $\mathrm{CO}_{2}$ in static mesenteric venous blood during intestinal ischemia and ischemic preconditioning in rats. Shock 16:403-408, 2001.

11. Moore-Olufemi SD, Kozar RA, Moore FA, Sato N, Hassoun HT, Cox CS, Jr., Kone BC: Ischemic preconditioning protects against gut dysfunction and mucosal injury after ischemia/reperfusion injury. Shock 23:258-263, 2005.

12. Carini R, Albano E: Recent insights on the mechanisms of liver preconditioning. Gastroenterology 125:1480-1491, 2003

13. Eisen A, Fisman EZ, Rubenfire M, Freimark D, McKechnie R, Tenenbaum A, Motro M, Adler Y: Ischemic preconditioning: nearly two decades of research. A comprehensive review. Atherosclerosis 172:201-210, 2004.

14. Claesson J, Lehtipalo S, Winso O: Do lung recruitment maneuvers decrease gastric mucosal perfusion? Intensive Care Med 29:1314-1321, 2003.

15. Nunes S, Rothen HU, Brander L, Takala J, Jakob SM: Changes in splanchnic circulation during an alveolar recruitment maneuver in healthy porcine lungs. Anesth Analg 98:1432-1438, 2004.

16. Odenstedt H, Aneman A, Karason S, Stenqvist O, Lundin S: Acute hemodynamic changes during lung recruitment in lavage and endotoxininduced ALI. Intensive Care Med 31:112-120, 2005.

17. Claesson J, Lehtipalo S, Bergstrand U, Arnerlov C, Winso O: Negative mesenteric effects of lung recruitment maneuvers in oleic acid lung injury are transient and short lasting. Crit Care Med 35:230-238, 2007.

18. Claesson J, Lehtipalo S, Bergstrand U, Arnerlov C, Rocksen D, Hultin M, Winso O: Intestinal circulation, oxygenation and metabolism is not affected by oleic acid lung injury. Clin Physiol Funct Imaging 25:357-363, 2005.
19. Lehtipalo S, Biber B, Frojse R, Arnerlov C, Johansson G, Winso O: Effects of dopexamine and positive end-expiratory pressure on intestinal blood flow and oxygenation: the perfusion pressure perspective. Chest 124:688-698, 2003.

20. Chiu CJ, McArdle AH, Brown R, Scott HJ, Gurd FN: Intestinal mucosal lesion in low-flow states. I. A morphological, hemodynamic, and metabolic reappraisal. Arch Surg 101:478-483, 1970.

21. Frojse R, Lehtipalo S, Bergstrand U, Biber B, Winso O, Johansson G, Arnerlov C: Local metabolic effects of dopexamine on the intestine during mesenteric hypoperfusion. Shock 21:241-247, 2004

22. Rixen D, Raum M, Holzgraefe B, Schafer U, Hess S, Tenhunen J, Tuomisto L, Neugebauer EA: Local lactate and histamine changes in small bowel circulation measured by microdialysis in pig hemorrhagic shock. Shock $18: 355-359,2002$

23. Solligard E, Juel IS, Bakkelund K, Johnsen H, Saether OD, Gronbech JE, Aadahl P: Gut barrier dysfunction as detected by intestinal luminal microdialysis. Intensive Care Med 30:1188-1194, 2004

24. Abrahamsson P, Winso O: An assessment of calibration and performance of the microdialysis system. J Pharm Biomed Anal 39:730-734, 2005.

25. Aksoyek S, Cinel I, Avlan D, Cinel L, Ozturk C, Gurbuz P, Nayci A, Oral U: Intestinal ischemic preconditioning protects the intestine and reduces bacterial translocation. Shock 18:476-480, 2002.

26. Aban N, Cinel L, Tamer L, Aktas A, Aban M: Ischemic preconditioning reduces caspase-related intestinal apoptosis. Surg Today 35:228-234, 2005.

27. Ljungdahl M, Rasmussen I, Ronquist G, Haglund U: Intramucosal $\mathrm{pH}$ and $\mathrm{pCO}(2)$ do not strictly correlate with intestinal energy metabolism in experimental peritonitis. Eur Surg Res 32:182-190, 2000.

28. Crissinger KD, Grisham MB, Granger DN: Developmental biology of oxidantproducing enzymes and antioxidants in the piglet intestine. Pediatr Res 25:612-616, 1989.

29. Blikslager AT, Roberts MC, Rhoads JM, Argenzio RA: Is reperfusion injury an important cause of mucosal damage after porcine intestinal ischemia? Surgery 121:526-534, 1997.

30. Tamion F, Richard V, Lacoume Y, Thuillez C: Intestinal preconditioning prevents systemic inflammatory response in hemorrhagic shock. Role of HO-1. Am J Physiol Gastrointest Liver Physiol 283:G408-G414, 2002.
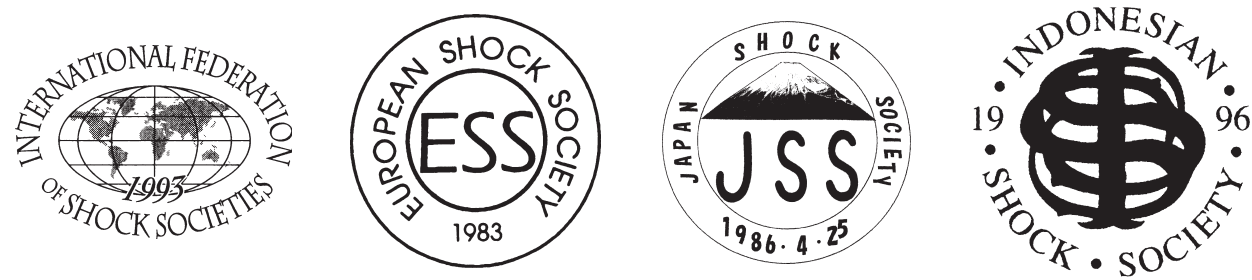